\title{
Microfibrillation of Coir Using High Speed Blender to Improvement of Tensile Behavior of Coir Reinforced Epoxy Composites
}

\section{Indra Mawardi, Jufriadi, and Hanif}

Politeknik Negeri Lhokseumawe, Department of Mechanical Engineering, Street Medan-Banda Aceh, Buketrata-Lhokseumawe, Aceh, 24301, Indonesia

\section{Abstract}

The trend of this research is focused on the development of coir fibre reinforced epoxy composites. Many researchers have been investigated the effects of coir fibre fibrillation on the tensile strength. The sorting treatment to this coir based on the uniformity of diameters and the fiber was cut between $10-20 \mathrm{~mm}$. The preliminary treatment was done by cooking the coir in $5 \% \mathrm{NaOH}$ solution in $80^{\circ} \mathrm{C}$ for approximately $10-15$ minutes. This process then can be addressed to the fibrillation process. This process was carried out by using a high-speed blender at 5 and 10 minutes, respectively. After that, the

Corresponding Author: Indra Mawardi ddx_72@yahoo.com

Received: 19 February 2019 Accepted: 5 March 2019 Published: 16 April 2019

Publishing services provided by Knowledge E

(c) Indra Mawardi et al. This article is distributed under the terms of the

Attribution License, which permits unrestricted use and redistribution provided that the original author and source are credited.

Selection and Peer-review under the responsibility of the ICBSA Conference Committee. composite was formed by hand lay-up, with the composition coir volume fraction and matrix of 20:80. The results show that the treated Coir can increase the composite tensile strength upto 14\%. The highest tensile Strength was obtained for EAC 10-10 composite on vial volume of $30 \%$ fiber and $70 \%$ epoxy i.e.53.70 MPa.

Keywords: coir, composites epoxy, fibrillation treatment, tensile strength

\section{Introduction}

Lately, the use of composite, especially in fiber-reinforced polymer composites has increased. Fiber reinforced polymer composites have significant potential in the field of engineering applications. The use of polymer composites cannot be separated from several advantages, such as low production costs, low density, corrosion resistance, insulators and manageable mechanics. The interface bond between fiber and matrix polymer is very important for composite compositions [1-5]. The use of natural fiber reinforced polymer composites with thermoplastic and thermoset matrices has been applied in various fields, starting in agriculture to automotive. The use of natural fiber begins in shifting synthetic fibers to reduce waste and utilization of natural resources that are renewable and biodegradable. Coconut fiber is a fiber that has the potential to be developed as a reinforcement in polymer composites. In his article Jayavani S et al. [6] has reviewed several modified methods of coconut fiber, it starts from the use of alkalis 
to the use of maleated as a coupling agent in thermoplastic and thermoset composites. The results of the review of composite fiber reinforced composites showed that hybrid composites had good mechanical properties. Polymer reinforced natural fiber composite products can be applied to the manufacture of funiture products, building materials and automotive products.

One of the natural fibers that has the potential to be developed as a composite reinforcement is coconut fiber. Coconut fiber is easily available and available in abundance. Coconut fiber is an alternative fiber that can be utilized in various industrial fields. The use of coconut fiber must be through chemical and mechanical treatment to improve the mechanical properties of the composite later. Research on the use of coconut fiber has been carried out by several previous researchers. Udaykumar et al. [7] has developed a polymer composite containing short fiber coconut fiber. Composites using a matrix of vinyl ester material with a heavy fraction of coconut fiber are $5 \%, 10 \%, 15 \% 20 \%$, and $25 \%$. Composites are formed by hand lay-up and in order to obtain mechanical properties, a bending test is carried out. Flexural properties increase with increasing percentage of fiber, but at certain weight percentages can reduce flexural properties. Optimal flexural properties are obtained from variations in coconut fiber weight of $20 \%$ with a composite thickness of $4 \mathrm{~mm}$. Composite reinforced coconut coir fiber with chemical fiber initial treatment has been carried out. The mechanical properties of green composites reinforced with coconut fiber with chemical initial treatment can improve mechanical properties and interface bonding. It looks also from the results of electron microscope (SEM) investigations which show an increase in fiber / matrix adhesion due to chemical fiber treatment [8].

R. Narendar et al. [9] have been developing the environmental friendly coir pithbased composites with a right balance of mechanical properties. Multilayered coir pith/nylon fabric/epoxy hybrid composites fabricated by the hand lay-up technique followed by compression moulding. A set of composites of same composition having chemically treated coir pith also prepared. Mechanical properties of composites such as tensile strength, impact strength, flexural strength, hardness, and abrasion resistance were evaluated. The hybridization with nylon fabric and the chemical treatment of coir pith enhances the mechanical properties of composites.

Hybrid fiber reinforced natural composites have also been developed by B. Bakri [10]. Hybrid composite reinforced rope and glass fiber and also unsaturated polyester resin as matrix composites. The hybrid composite is formed by the volume volume fraction and with a matrix of 30:70. The fraction variations in the coir rope and glass fiber volume are 10:20, 15:15 and 20:10. Impact tests on 15:15 fiber volume fraction 
yield the highest impact energy and impact strength, when compared to the other two variations, respectively $12.8 \mathrm{~J}$ and $177.1 \mathrm{~kJ} / \mathrm{m}^{2}$. Composite reinforced natural fibers such as banana fiber, coconut fiber and sisal have also been studied using epoxy matrices. The impact energy produced was 4 joule coir respectively, banana was 5 , sisal was 4 joule [11]. Karthikeyan et al. [12] have investigated the effect of treatment of coco fiber with sodium lauryl sulfate (SLS). Epoxy composites are formed with variations in fiber treatment using SLS concentrations of $2 \%, 4 \%, 6 \%, 8 \%$ and $10 \%$. As a comparison test, fiber is also treated with $\mathrm{NaOH}$. Epoxy composites using fiber treatment using SLS which produce better impact energy than composites with $\mathrm{NaOH}$ fiber treatment. Epoxy composites reinforced with coconut fiber with randomly oriented fibers produce tensile strength of $31.08 \mathrm{MPa}$ and impact strength of $11.49 \mathrm{~kJ} / \mathrm{m}^{2}$. This composite is recommended for use in small loads [4]. Mechanical properties, the tensile strength of epoxy composites with hemp fiber reinforcement has a better value compared to epoxy composites reinforced with coconut fiber. This is inversely proportional to the mechanical properties of flexural strength, where epoxy composites reinforced coconut coir fibers are higher than those of hemp fiber reinforcement [13].

Junpeng $D$ et al. [14] have conducted a research on the use of hybrid fibers as bio composite reinforcement. Sisal fiber and coconut coir fibers are used as reinforcement with polylactide (PLA) as a matrix. Fiber was varied by alkali treatment (ASF and ACF) and without alkali treatment (USF and UCF). The results showed that the mechanical properties of fiber-reinforced bio composite with alkali treatment had advantages, when compared with the use of fiber without alkali treatment. PLA bio composite is reinforced by ASF/ACF has superior mechanical properties at a ratio of 7: 3 for sisal fibers and coconut fibers.

The mechanical properties of natural fiber-reinforced composites are strongly influenced by the interface between fibers and matrices. In addition, the mechanical properties of composites are also strongly influenced by the type of fiber used, the volume of fiber in the matrix, the orientation of the fiber and the type of matrix used. Addition of coupling agent and chemical treatment can increase the interface between fibers and matrix. [15]. Narendra et al. [16] have developed hybrid epoxy composites with coir pith reinforcement and nylon fabric. The developed hybrid composites have better durability when in humid conditions. Composite reinforced sisal fiber with $18 \% \mathrm{NaOH}$ treatment produced better tensile and flexural strength compared with sisal fibers with $5 \%$ and $10 \%$ $\mathrm{NaOH}$ treatment [17]. Testing of mechanical properties for HDPE polymer composites reinforced with sisal fibers has been investigated by [18]. The results of the study show 
that mechanical properties increase with the fiber content in composite up to a certain limit.

The addition of micro- $\mathrm{Al}_{2} \mathrm{O}_{3}$ to carbon fiber reinforced polymer composites has been carried out. Dynamically composite crack toughness, impact strength and interlaminar flexural strength (mode II). The addition of micro- $\mathrm{Al}_{2} \mathrm{O}_{3}$ to carbon fiber reinforced polymer composites produced fracture toughness, impact strength, and optimum flexural strength in a row of $522 \mathrm{~J} / \mathrm{m}^{2}, 161.7 \mathrm{~kJ} / \mathrm{m}^{2}$ and $759 \mathrm{MPa}$ [19]. Leandro José da Silva et al. [20] have designed a factorial of hybrid composites reinforced with natural fibers with silica particle fillers. Hybrid composites reinforced sisal fibers with directional orientation. This study aims to look at the effect of silica particles, maleate fiber, and anhydride volume fractions on the mechanical properties of composites. The results of the study showed that the micro silica particles did not have a significant effect on flexural strength. Micro silica particles, volume fraction and addition of maleic anhydride influence the flexural modulus. The characteristics of laminated composites increased with the addition of 25\% silica nanoparticles in the epoxy resin matrix [21]. Addition of $1 \%$ nanoclay (heavy fraction) to epoxy composites increases impact strength and tensile strength. This is also followed by increasing the elastic modulus of the epoxy composite $[22,23]$. Research to see the effect of nanoclay on epoxy composites has been done. Addition of nanoclay weighing 3 and $5 \%$ has increased composite compressive strength by an amount of $22 \%$ and $36 \%$ [24]. The fibrillation treatment of coir for 10 minutes had an impact on the flexural strength of the epoxy composite, with impact and flexural strength of $24.45 \mathrm{~kJ} / \mathrm{m}^{2}$ and $87.91 \mathrm{MPa}$ [25]

Satender et al. [26] have examined the coir usage as an epoxy composite amplifier. The different weight ratio of coir fibers to epoxy resin was investigated. The tensile test, impact test and hardness test were conducted on the prepared specimens to evaluate the mechanical properties. Regarding the experiment, the addition of coir fibers increases the strength of composite; the composite with 7.5\% fiber content shows the maximum tensile and impact strength. Seenivas et al. [27] in his present work, the mechanical properties (tensile, flexural, compression and hardness) are tested for sisal/coir; sisal/hemp and sisal/flax fibers reinforced epoxy hybrid composites based on the ASTM standard. Sisal/hemp fibers reinforced hybrid composite exhibits more tensile and flexural strength than sisal/coir and sisal/flax fiber reinforced hybrid composites.

The mechanical properties of fiber-reinforced composites are strongly influenced by fiber diameter and fiber length. The smaller the diameter of the fiber, the better the interface bond will be. The better the interface between fibers and matrices will increase the composite characteristics. The chemical fiber treatment is not good enough 
to increase the interface bond. Microfibrillation of fibers mechanically needs to be investigated to see the level of reduction in fiber diameter, especially coconut fiber. The research objective is to observe the effect of microfibrillation of coconut coir in semi-mechanical by using high-speed blender in order to reduce the fiber diameter to increase the tensile stress of the coconut fiber reinforced composites.

\section{Meterials and Methods}

\subsection{Materials}

The coir fibers are from the local resources Aceh, Indonesia (Fig. 1). Alumina $\left(\mathrm{Al}_{2} \mathrm{O}_{3}\right)$ with a $99 \%$ purity rate is used as a filler. Eposchon type $A$ is used as the epoxy resin (bispenola epichlorohydrin), and type B for epoxy hardener (polyaminoamide) with a ratio of 1: 1. All epoxy resin is supplied by PT. Justus Kimia Raya.

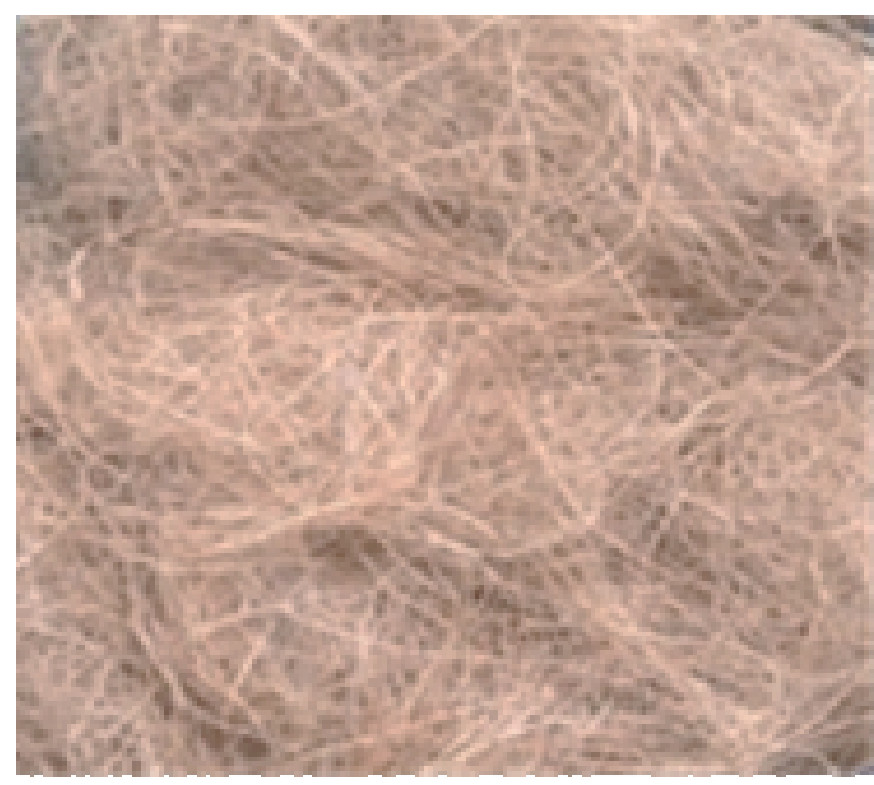

Figure 1: Coir Fibers.

\subsection{Microfibrillation of fiber}

Coir fiber husks are sorted in uniform diameter and cut $10-20 \mathrm{~mm}$ long. The fiber is boiled in a $5 \% \mathrm{NaOH}$ solution at $80{ }^{\circ} \mathrm{C}$ for 10 minutes and 15 minutes. The pre-treatment fibers are then continued to the fibrillation process. Semi-mechanically high-speed blender carries out the fibrillation rate process. The Coir is blended at 20,000 rpm for 5 and 10 minutes to reduce fiber diameter. The fibrillated fibers then washed with aquades and dried for 3 (three) days before composite printing. This process is related to Uetani 
research [28] et al. that performs nanofibrillation using a high-speed blender. Nanofiber with an average diameter of 15-20 nm was successfully prepared from a chitin substance processed with a blender speed of 34000 rpm for 30 minutes with a fiber concentration of $0.7 \%$ wt.

\subsection{Composite fabrication}

The process of forming a composite panel is done using a mold made of steel with the hand lay up method. The formation process is carried out at room temperature. Epoxy resin, alumina and hardener were mixed in a bowl to prepare the matrix materials. A well-mixed mixture of matrix and coir was poured into the mold. Use of alumina 5\% by weight of epoxy. Compositions of the volume fraction of coir and matrix are 20:80, 30:70, and 40:60. The steps involved in the composites fabrication is shown in Fig. 2.

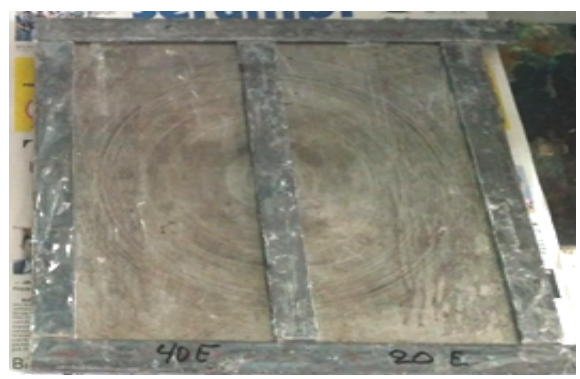

Mould of composite

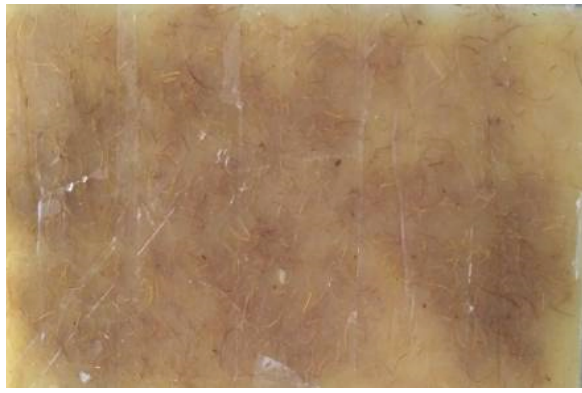

Composite
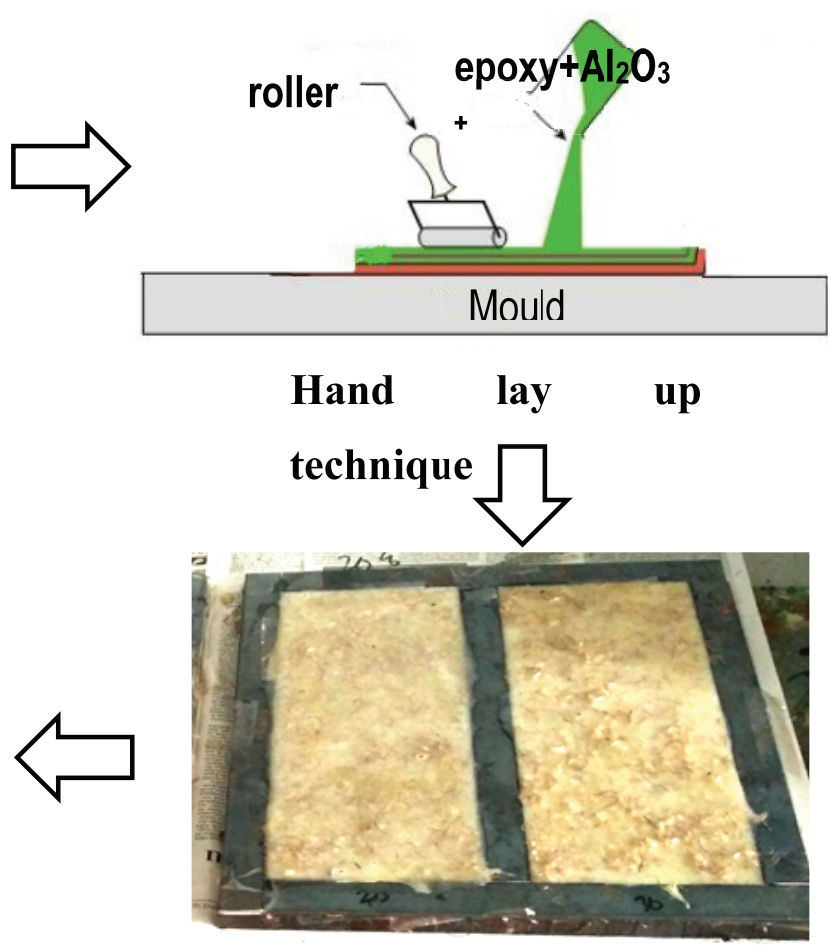

Mixture of matrix and rienforcement

Figure 2: Steps fabrication of composites. 


\subsection{Testing of the composites}

The fabricated composite is formed into a tensile test specimen. The tensile test was carried out according to ASTM D3039 standard (Fig. 3) The fractured surface morphology of the composite specimens was examined using scanning electron microscope (SEM).



Figure 3: Dimensional specimen of tensile test.

\section{Results and Discussions}

Coir reinforced composites with various varieties of fiber microfibrillation treatment have been carried out tensile testing. Composite epoxy with 10 minutes of fiber cooking and blend for 5 minutes (EAC10-5), epoxy composites with 15 minutes of fiber cooking and blend for 5 minutes (EAC15-5) and there are three comparators to see the results of fiber treatment, epoxy (E), epoxy $+\mathrm{Al}_{2} \mathrm{O}_{3}(\mathrm{EA})$ and epoxy $+\mathrm{Al}_{2} \mathrm{O}_{3}+$ Coir without treatment (EAC).

The results of tensile strength and tensile modulus of coir-reinforced composites with fiber cooking treatment for 10 and 15 minutes and blender process for 5 min for various variations of volume fraction are shown in Figs. 4 and 5.

Fig. 4 shows a coated fibrillated epoxy composite, EAC10-5 and EAC $15-5$ having a 14\% increase in tensile strength compared with a coated fiber-reinforced epoxy composite $(E A C)$. The increased tensile strength is affected by its reduced factor fiber diameter after undergoing fibrillation process using a high-speed blender (Fig. 5). The fiber diameter becomes smaller will improve the interface between fiber and matrix.

The highest tensile strength occurs in the coated fiber-reinforced epoxy composite, EAC10-5 with a composition of 30:70, ie $52.43 \mathrm{MPa}$. In the same composition (30:70), the composite EAC10-5 produced 11\% greater tensile strength than the EAC15-5 composite of only $46.68 \mathrm{MPa}$. The occurrence of tensile strength reduction in coir-reinforced 


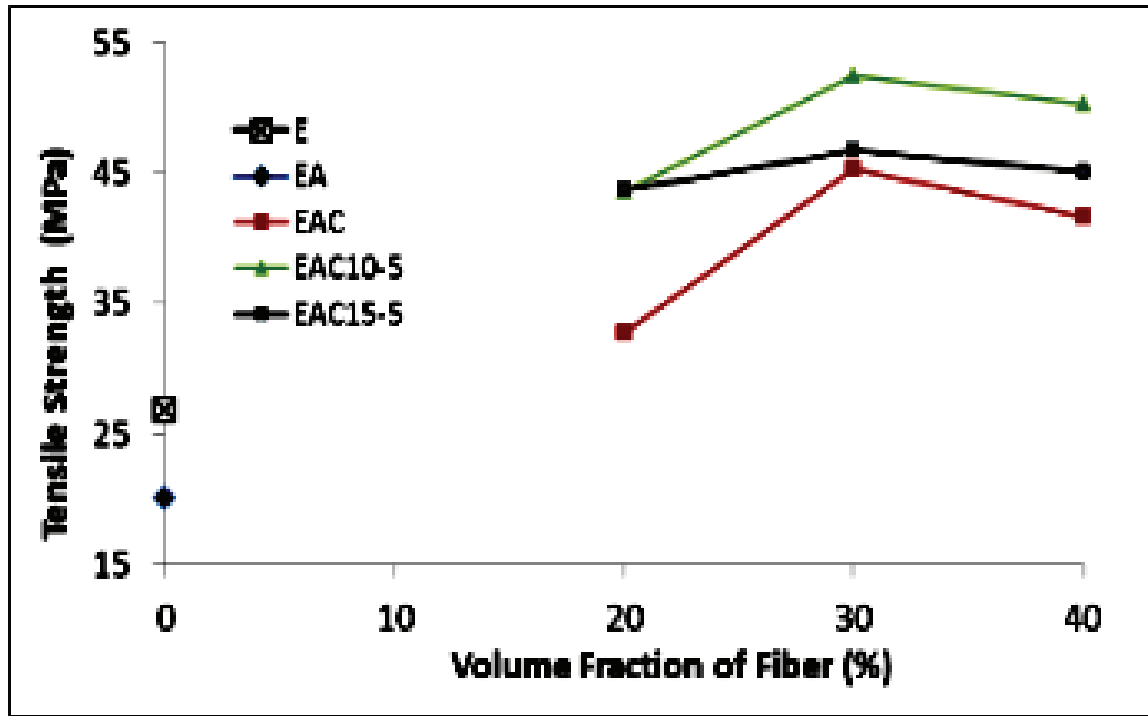

Figure 4: Composite tensile strength with fiber fibrillation for 5 minutes.

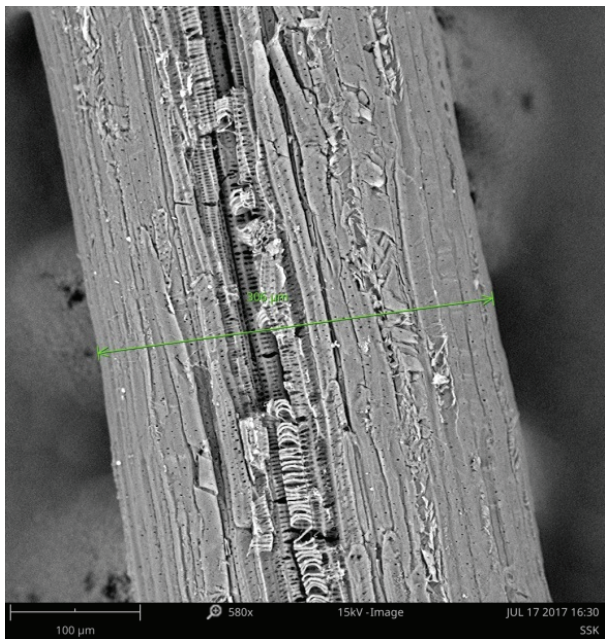

(a)



(b)

Figure 5: Coir before and after fibrillation: (a) Coir before fibrillation and (b) coir after fibrillation.

composites with longer cooking treatment, 15 minutes, due to degradation of the coir structure. Coir degradation causes coir strength to decrease. This phenomenon can be seen from the results of SEM (Fig. 6).

A similar phenomenon also occurs in epoxy composites reinforced coir with a 10 minute blender time. The coated composite epoxy composite with the EAC10-10 variation on the 30:70 composition has the highest tensile strength, which is $53.70 \mathrm{Mpa}$ and the lowest is 34.65 Mpa on the EAC15-10 composite with 20:80 fraction volume. The coated-coated epoxy composites having fibrillation treatment, EAC10-10 and EAC 15-10 also experienced a $15 \%$ increase in tensile strength compared to coagulated coir-treated composites (EAC) (Fig. 7). 


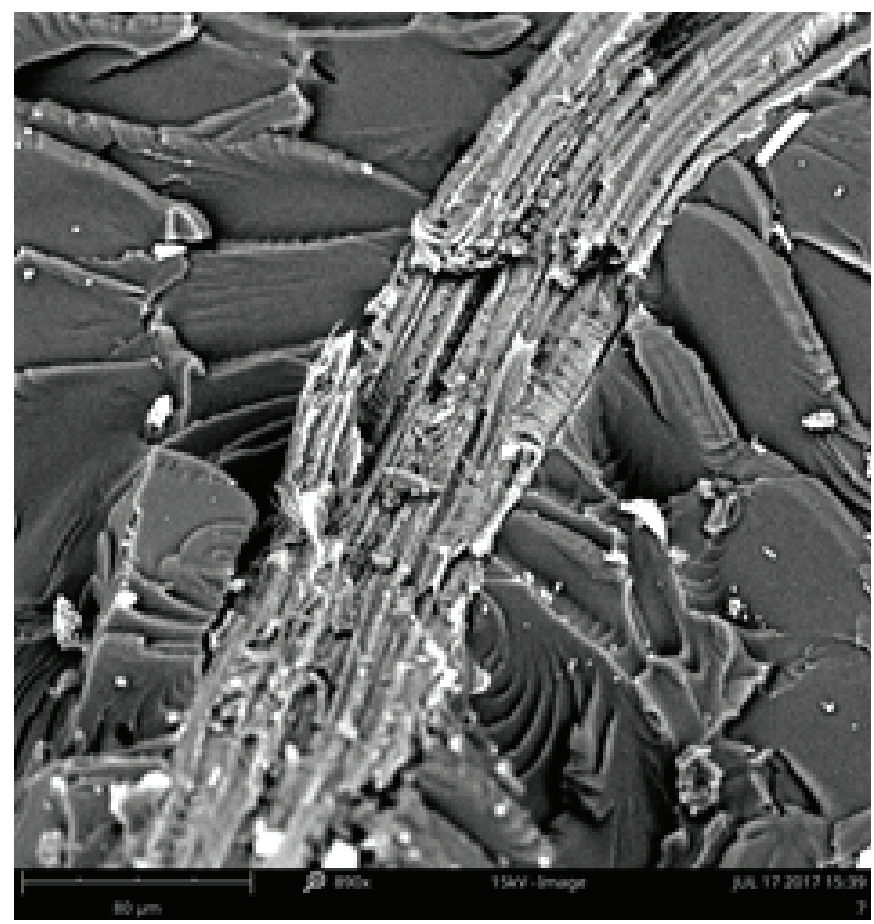

Figure 6: Coir structure due to fibrillation for 15 minutes.



Figure 7: Tensile strength composite with fiber blender for 10 minutes.

In this case, an increase in coir treatment cooked from 10 minutes to 15 minutes can reduce tensile strength by up to $27 \%$. Longer time stability will damage the fiber structure thus lowering the tensile strength value of coir-reinforced epoxy composites.

When viewed from variations of composite-forming compositions, coir and epoxy $(20: 80,30: 70$, and 40:60) and fiber fibrillation treatment, the composition with volume fraction of $30 \%$ fiber and $70 \%$ overall epoxy yielded higher tensile strength values compared with the composition of 20:80 and 40:60 (Fig. 8). EAC10-10 coir-reinforced 
composites yield better tensile strength than composites with other treatment fibrillation variations, EAC10-5, EAC15-5, and EAC15-10.

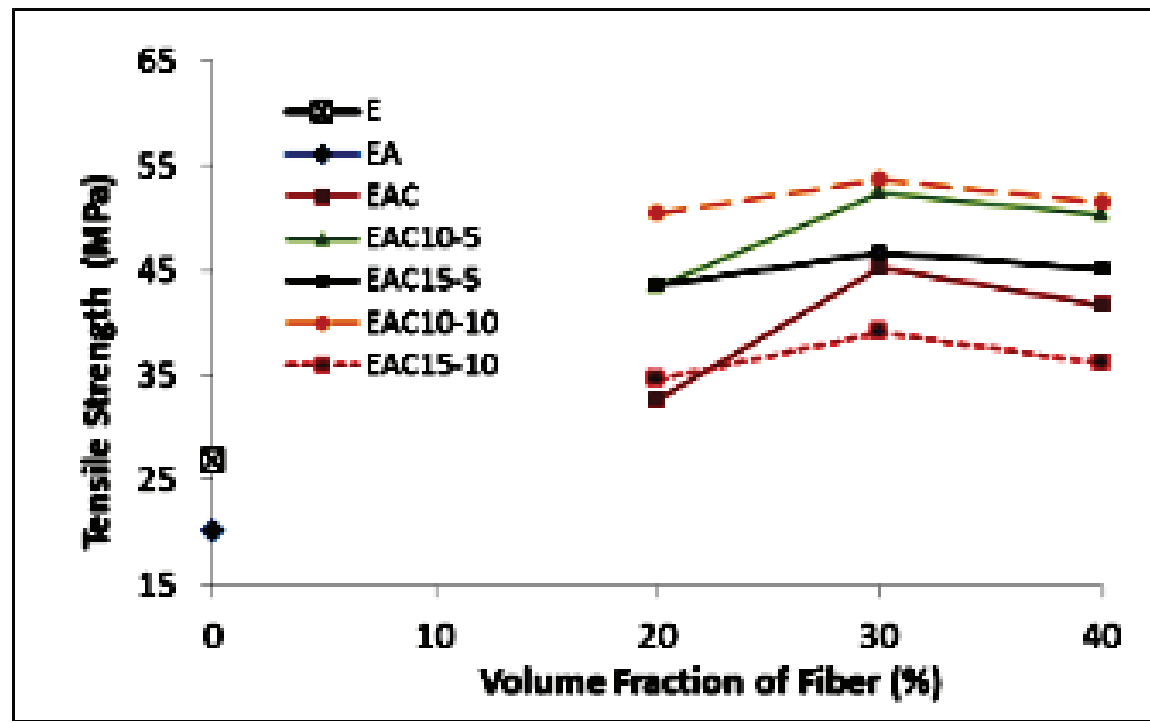

Figure 8: Comparison of composite tensile strength with treatmentfiber blender process for 5 and 10 minutes.

Microfibrillation manufacture of coir using high speed blender has produced tensile strentgh from epoxy composites which is better than epoxy composites reinforced with coir without microfibrillation process. Some results of comparative research have conducted by [29] and [30]. Testing the mechanical properties of coir epoxy composites for the formation of shell helmets has been carried out $[29,30]$. It was observed that the tensile strength of coir fiber/epoxy resincomposites was maximum at $30 \mathrm{wt} \%$ filler loading (23.68 MPa). Investigation using natural fiber tools, namely bamboo with Poly lactic acid (PLA) matrix has been carried out by [2]. Bamboo fibers, as a raw cellulose source, were used to prepare microfibrillated cellulose (MFC) using a high speed blender at 20,000 rpm for 60 minutes. It can be found that the addition of the MFC network in the PLA resin can increase Young's modulus and tensile strength from 2.4 to $3.1 \mathrm{GPa}$ and 32.8 to $38.7 \mathrm{MPa}$, respectively [30].

With a lifetime estimation of composites that is quite long, the results of this study were very suitable to be applied to boat manufacturing, automotive products, helmet shells, bullet-proof vests, and other environmentally friendly engineering products. The novelty of the research is the method of boiling coir fiber and the length of the microfibrillation process using a high-speed blender to produce the optimal diameter of coir.

Chemical treatment of coconut fiber (using $\mathrm{NaOH}$ ) and followed by the fibrillation process using high speed blender is an alternative process to reduce the dimensions of fiber diameter. After fibrillation due to the reduced diameter of the fibre, the aspect 
ratio of the fiber increases and yields rough surface topography, which in turn offers a better fibre-matrix interface. This results in obtaining the enhanced properties. In the fracture surface, the fibers are disconnected and there is no marked out of the loop due to the release of the fibers, named pull outs bonding (Fig.9).



Figure 9: Topography of pull out bonding on fracture surface.

\section{Conclusions}

The result of tensile strength test of epoxy composite reinforced coit, with coir treatment by microfibrillation can be concluded:

1. The treatment of fiber fibrillation can increase the fiber-matrix interface, thereby enhancing the mechanical properties of the composite

2. The highest tensile strength is produced by EAC10-10 composite on vial volume of $30 \%$ fiber and $70 \%$ epoxy, ie $53.70 \mathrm{MPa}$.

3. Fiber fibrillation by cooking for 10 minutes and blending for 10 minutes produces a coir structure that can increase the tensile strength of the composite. 


\section{Acknowledgments}

Acknowledgments are submitted to Kemenristekdikti for funding assistance provided through a research grant with an applied product research scheme in 2018 .

\section{References}

[1] Verma D, Gope PC, Shandilya A, Gupta A. Coir fibre reinforcement and application in polymer composites. J. Mater. Environ. Sci. 2013;4(2):263-276.

[2] Salleh Z, Islam M, Yusop M. Mechanical properties of activated carbon (AC) coconut shell reinforced polypropylene composites encapsulated with epoxy resin. International Conference on Chemical, Biological and Environmental Engineering APCBEE Procedia 2014;9:92-96.

[3] Mulinari DR, Baptista CARP, Souza JVC. Mechanical properties of coconut fibers reinforced polyester composites. International Journal of Engineering Research, Procedia Engineering 2011;10:2074-2079.

[4] Harisha S, Michael PD, Bensely A, Mohan LD. Mechanical property evaluation of natural fiber coir composite. Materials Characterization 2009;60:44-49.

[5] H. Alamri H, Low IM. Mechanical properties and water absorption behaviour of recycled cellulose fibre reinforced epoxy composites. Elsevier Polymer Testing 2012;31(5):620-628.

[6] Jayavani S, Harekrishna Deka, T.O. Varghese, S.K. Nayak. Recent development and future trends in coir fiber-reinforced green polymer composites: Review and evaluation, J Polymer Composites 2016;37(11) 3296-3309

[7] Udaykumar PA, Rajanna S, Ramalingaiah. Studies on effects of short coir fiber reinforcement on flexural properties of polymer matrix.J IJRET 2014;03(02):37-41.

[8] Asasutjarit, Chankan, Charoenvai, Sarocha, Hirunlabh, Jongit, Khendari, Joseph. Materials and mechanical properties of pre-treated coir based green composites. Elsevier Composite Part B 2009;7:633-637.

[9] R. Narendar, K. Priya Dasan, Jeenet Jayachandran, Effect of hybridization and chemical treatment on the mechanical properties of coir pith/nylon/epoxy hybrid composites, J Polymer Composites 2016;37(3) 649-657.

[10] Bakri B, Chandrabakty S, Soe R. Mechanical properties of coir rope-glass fibers reinforced polymer hybrid composites,IJJSMM 2015;2(2):132-135.

[11] Sakthivel M, Ramesh S. Mechanical properties of natural fibre (banana, coir, sisal) polymer composites. J Science Park 2013;1(1) 234-240. 
[12] Karthikeyan A, Balamurugan K, Kalpana A. 2013. The new approach to improve the impact property of coconut fiber reinforced epoxy composites using sodium lauryl sulphate treatment. Journal of Scientific \& Industrial Research 2013;72(3):132-136.

[13] Akash, Venkatesh G, Sreenivas RKV, Prasad CB, Prabilsonkhadka. Comparative evaluation of mechanical and water absorption properties of pure epoxy resin, coir fiber/epoxy resin and hemp fiber/epoxy resin composite. J. IJAER 2015;10(55).

[14] Junpeng Duan, Hongwu Wu, Wuchang Fu, Mingyang Hao, Mechanical properties of hybrid sisal/coir fibers reinforced polylactide biocomposites, J Polymer Composites 2017;38(7).

[15] Alex S, Stanly JR, Ramachandran M. A review on biodegradability of hybrid bamboo/glass fiber polymer composites. International Journal of Applied Engineering Research 2015;10(11);10565-10569.

[16] Narendar R, Priya DK, Muraleedharan N. Development of coir pith/nylon fabric/epoxy hybrid composites. J Materials and Design 2014;54: 644-651.

[17] NoorunnisaKP, Abdul K, Ramachandra R,Venkata N. Tensile, flexural and chemical resistance properties of sisal fibre reinforced polymer composites: effect of fibre surface treatment. J Polym Environ 2011;19:115-119.

[18] Xuefeng Z, Robert KYL, Shu-Lin Bai. Mechanical properties of sisal fiber reinforced high density polyethylene composites: Effect of fiber content, interfacial compatibilization, and manufacturing process. Elsevier Composites Part A: Applied Science and Manufacturing 2014;65:169-174.

[19] Zhi Wang, Xueyou Huang, Longbin Bai, Ruikui Du, Yaqing Liu,Yanfei Zhang, Guizhe Zhao. 2016. Effect of micro- $\mathrm{Al}_{2} \mathrm{O}_{3}$ contents on mechanical property of carbon fiber reinforced epoxy matrix composites, Elsevier Composites Part B 91 2016:392-398.

[20] Leandro José da Silva, Túlio Hallak Panzera, Vânia Regina Velloso, André Luis Christoforo, Fabrizio Scarpa. 2012. Hybrid polymeric composites reinforced with sisal fibres and silica microparticles. Elsevier Composites Part B 43 2012:3436-3444.

[21] Mahrholz T, Stängle J, Sinapius M. Quantitation of the reinforcement effect of silica nanoparticles in epoxy resins used in liquid composite moulding processes. Composite Part A 2009;40:235-243.

[22] Isik I, Yilmazer U, Bayram G. Impact modified epoxy/montmorillonite nanocomposites: synthesis and characterization. Polymer 2003;44:6371-7.

[23] Yasmin A, Abot JL, Daniel LM. Processing of clay/epoxy nanocomposites by shear mixing. J Scripta Mater 2003;49:81-6. 
[24] Subramaniyan AK, Sun CT. Enhancing compressive strength of unidirectional polymeric composites using nanoclay. Elsevier Composites Part A: Applied Science and Manufacturing 2006;37(37):2257-2268.

[25] I Mawardi, Jufriadi, and Hanif. Effect Of Fiber Fibrillation on Impact And Flextural Strength Of Coir Fiber Reinforced Epoxy Hybrid Composites. IOP Conf. Series: Materials Science and Engineering 334 (2018) 012079.

[26] Satender K, Kakali D, Suresh P. 2016. Mechanical properties of coconut fiber reinforced epoxy polymer composites. Jurnal Irjet 2016;03(07):1334-1336.

[27] Sreenivas KVR, Venkatesha G, Akash, Sanjeevamurthy. Mechanical properties of natural fiber reinforced hybrid composites. J ARPN 2016;11(1):253-258.

[28] Uetani K, Yano H. Nanofibrillation of wood pulp using high-speed blender. J Boimacromolecules 2010;12(2):348-353.

[29] Supachok TANPICHAI and Jatuphorn WOOTTHIKANOKKHAN. Mechanical properties of Poly(lactic acid) Composites Reinforced with Microfibrillated Cellulose Prepared Using High Speed Blending. Journal of Metals, Materials and Minerals, Vol.24 No.2 pp.55-60, 2014.

[30] Chizoba Obele and Edith Ishidi. Mechanical Properties of Coir Fiber Reinforced Epoxy Resin Composites for Helmet Shell. Industrial Engineering Letters. Vol.5, No.7, pp. 67-74, 2015. 